https://helda.helsinki.fi

The tragedy of the commons in evolutionary biology.

Rankin, Daniel J.

2007

Trends Ecol Evol. 2007 Nov 2;

http://hdl.handle.net/1975/7498

http://dx.doi.org/10.1016/j.tree.2007.07.009

Downloaded from Helda, University of Helsinki institutional repository.

This is an electronic reprint of the original article.

This reprint may differ from the original in pagination and typographic detail.

Please cite the original version. 


\section{The Tragedy of the Commons in Evolutionary Biology}

3 Daniel J. Rankin ${ }^{1,2}$, Katja Bargum ${ }^{3}$ and Hanna Kokko ${ }^{2}$

4 1) Division of Behavioural Ecology, Institute of Zoology, University of Bern,

5 Wohlenstrasse 50a, CH-3032 Hinterkappelen, Switzerland

6 2) Laboratory of Ecological and Evolutionary Dynamics, Department of Biological

7 and Environmental Science, PO Box 65 (Biocenter 3, Viikinkaari 1), University of

8 Helsinki, 00014 Helsinki, Finland

9 3) Team Antzz, Department of Biological and Environmental Science, PO Box 65

10 (Biocenter 3, Viikinkaari 1), University of Helsinki, 00014 Helsinki, Finland

11 Author E-mail addresses: DJR: daniel.rankin@esh.unibe.ch, KB:

12 katja.bargum@helsinki.fi, HK: hanna.kokko@helsinki.fi

13 Corresponding author: Division of Behavioural Ecology, Institute of Zoology,

14 University of Bern, Wohlenstrasse 50a, CH-3032 Hinterkappelen, Switzerland

15 Telephone: +41786489905

16 Manuscript information: No. pages (including title page): 34. No. figures: 2 (1 in 17 box). No. Boxes: 2. No Tables: 2. 


\section{$1 \quad$ Abstract}

2 Garrett Hardin's tragedy of the commons is an analogy that shows how

3 individuals driven by self-interest can end up destroying the resource

4 upon which they all depend. The proposed solutions for humans rely on

5 highly advanced skills such as negotiation, which raises the question

6 of how non-human organisms manage to resolve similar tragedies. In recent

7 years, this question has promoted evolutionary biologists to apply the

8 tragedy of the commons to a wide range of biological systems. Here we

9 provide tools to categorize different types of tragedies, and review

10 different mechanisms that can resolve conflicts that could otherwise end

11 in tragedy, including kinship, policing and diminishing returns. A

12 central open question, however, is how often biological systems are able

13 to resolve these scenarios rather than drive themselves extinct through

14 individual-level selection favouring self-interested behaviours.

\section{The Tragedy of the Commons}

17 The tragedy of the commons (see glossary) provides a useful analogy allowing us to

18 understand why shared resources, such as fisheries or the global climate, tend to

19 undergo human overexploitation [1]. The analogy, which dates back over a century

20 prior to Hardin's original paper [2], describes the consequences of individuals

21 selfishly over-exploiting a common resource. The tragedy of the commons was

22 originally applied to a group of herders grazing cattle on a common land. Each herder

23 only gains a benefit from his own flock, but when a herder adds more cattle to the 
1 land to graze everyone shares the cost, which comes from reducing the amount of

2 forage per cattle. If the herders are driven only by economic self-interest, they will

3 each realize that it is to their advantage to always add another animal to the common:

4 they sacrifice the good of the group (by forgoing sustainable use of the resource) for

5 their own selfish gain. Thus, herders will continue to add animals, eventually leading

6 to a "tragedy" where the pasture is destroyed by overgrazing [1].

7 The difficulties inherent in protecting shared common resources, such as marine

8 stocks or clean air, are well known: while everyone benefits from an intact resource,

9 there is an individual-level temptation to cheat (e.g. to overexploit or pollute) because

10 cheating brings economic advantages to the individual while costs are distributed

11 among all individuals (see box 1). The lesson drawn from these studies is that solving

12 the dilemma often requires negotiation and sanctions on disobedient individuals. This

13 changes the payoffs, so that group-beneficial behaviour also becomes optimal for the

14 individual: an example would be imposing heavier taxes on polluting industries.

15 Hardin's own main solution to the tragedy of the commons was state governance and

16 privatization of the resource in question [1]; in general, social norms as well as

17 individual morality have been considered good candidates for preventing

18 overexploitation of common resources.

19 Despite citing Lack's work on population regulation [3] to contrast population

20 regulation in birds with human population growth, Hardin did not venture to extend

21 his analogy to the problems of evolutionary ecology. However, if the tragedy can only

22 be avoided when higher-level incentives are invoked, as in the case of legal

23 incentives, this raises the question of how non-human organisms can avoid

24 overexploiting the resources they depend on. After the group selection debate of the 
1 1960s [4], it should be clear that this question is not trivial: natural selection acts

2 primarily at the level of the gene, and therefore favours individuals which serve their

3 own selfish interests [5]. Nevertheless, it is only in the last decade that the tragedy of

4 the commons analogy has become increasingly used by evolutionary biologists (Table

5 1) to explain why selfish individuals in animal and plant populations do not evolve to

6 destroy the collective resource [e.g. 6, 7-13].

7 A tragedy of the commons in evolutionary biology refers to a situation where

8 individual competition over a resource reduces the resource itself, which can in turn

9 reduce the fitness of the whole group [14]. The tragedies discussed here can apply to a

10 range of levels: groups, population or species. The concept has been used in a

11 diversity of fields in biology, ranging from plant-competition for resources [e.g. 7] to

12 the evolution of cooperation and conflict in insect societies [e.g. 9]. What the

13 tragedies have in common is that individuals are selfishly maximizing their own

14 fitness at the expensive of the productivity of the group or population. Here we seek

15 to review how the tragedy of the commons is used in the literature, with the hope of

16 highlighting that the underlying principles are the same, regardless of the system or

17 the level at which the tragedy of the commons occurs.

\section{Types of tragedies}

19 Despite the relatively recent acquisition of the tragedy of the commons analogy into 20 evolutionary biology [but see 14], not all studies use the same definition for a tragedy

21 of the commons, and there are many related terms (see glossary). As confusing

22 terminology can hinder the development of a field [15], here we seek to define

23 different forms of the tragedy of the commons (tables 1 and 2). What these tragedies

24 all have in common is that individual selfishness reduces the resource over which 
1 individuals are competing, and lowers group fitness. The tragedy of the commons in

2 evolutionary biology therefore encompasses what social scientists call a public good

3 game, or an N-person prisoner's dilemma [e.g. 16].

$4 \quad$ Resources prone to a tragedy of the commons

5 One can distinguish between three types of group-level costs of competition, which

6 may result in a tragedy of the commons (Table 2). The first, which fits exactly with

7 Hardin's original analogy, involves individuals selfishly exploiting a common

8 resource until the resource is reduced to the point that the individuals no longer can

9 persist on it. Examples include simple competition for food, but reproductive traits

10 can also be involved, such as high virulence in parasites [17] and laying larger

11 clutches in an attempt to out-reproduce others. While it has been suggested that only

12 competition over an extrinsic resource should be viewed as a tragedy of the commons

13 [e.g. 18], evolutionary biologists have applied the term to a much wider range of

14 contexts [e.g. $6,8,9,12,19]$. Figure 2 a shows the case of bacteriphages surrounding a

15 bacteria [12], a system which is prone to a tragedy of the commons when the

16 virulence of the phages becomes so high that they destroy the bacterio on which they

17 exist.

18 While Hardin's analogy was originally applied to the over-exploitation of an external

19 resource, evolutionary biologists have realised that the analogy reflects a wide range

20 of social dilemmas, and can potentially unify a number of fields. The tragedy of the

21 commons has mostly been applied to social goods formed by cooperation (see tables 1

22 and 2). Social goods come in two, analogous forms. Most commonly the definition of

23 a tragedy of the commons has been extended to cover what we term "social goods"

24 (also known as public goods, illustrated by the example of stalk production in figure 
$12 \mathrm{~b})$. These are cases where the resource does not exist extrinsically, instead it arises in

2 a social context either through individuals investing in cooperation, or restraining

3 from engaging in conflict with conspecifics. In the case of cooperation being the

4 social good (type $2 \mathrm{a}$ in table 2 ), the tragedy of commons arises if non-contributing

5 cheaters can gain their share of the common goods provided by cooperating

6 individuals [e.g. 20]. Behaviours vulnerable to such a tragedy include sentinel

7 behaviour in cooperatively breeding meerkats [e.g. 21], invertase production in yeast,

8 which helps groups of yeast cells to break down sucrose, [22] or workers choosing to

9 work rather than reproduce in social insect colonies [9].

10 For example, individuals of the bacteria Myxoccocus xanthus cooperate to form

11 complex fruiting structures which release spores. "Cheating" individuals, which don't

12 invest in building non-spore parts of the fruiting structures, produce more spores than

13 wild type individuals, and can therefore invade and destroy the social good, causing

14 the population to go extinct [19]. In all of these cases, a well functioning unit

15 produces the best group fitness (i.e. mean fitness per individual), but it may be

16 advantageous for the individual in question to free-ride and not contribute to the

17 social good.

18 The second type of social good (type $2 \mathrm{~b}$ in table 2 ) involves individuals restraining

19 from potentially competitive acts. For example, in territorial conflicts, the resource

20 (the area over which fighting occurs) may remain intact, but the costs are paid by

21 individuals who spend energy and time fighting. Engaging in conflict brings costs to

22 all group members, either through increased injury or having to invest more in

23 conflict. This is best illustrated by the case of plant competition for light (figure 2c),

24 where the extrinsic resource (light) remains intact [10]. Taller plants gain more access 
1 to light in order to compete with their neighbours, and so are relatively more

2 successful than shorter plants. But height cannot be achieved without investment in

3 sturdy vertical biomass. Selection therefore favours plants that grow taller and shade

4 their shorter neighbours. But any attempt to outgrow one's neighbour is a zero-sum

5 game (see Glossary). Therefore, assuming that vertical structures contribute nothing

6 to fecundity, we can predict taller trees, but less overall productivity. Such investment

7 is wasteful at the group level in a similar vein when people sitting in audiences are

8 forced to stand up if the first rows do so, until everyone pays the cost of having to

9 stand up without any remaining improvement in the view to the stage. Tall plant

10 populations, which likewise invest in an essentially zero-sum game, are indeed less

11 productive [10].

12 This example highlights how not all competition is 'tragic'. If plant A outcompetes

13 plant $\mathrm{B}$, so that $\mathrm{A}$ through gaining all the light is equally productive as the whole

14 group of A and B would have been in a non-competitive situation, there is no tragedy.

15 But the investment necessary to outcompete others may give rise to a tragedy, as such

16 investment reduces overall productivity. Individuals can then be argued to have

17 destroyed the common good created by restraining from competition. In other words,

18 collectively the group would do better if all plants were shorter, but individuals which

19 invest in taller structures gain more light themselves and shade their conspecifics, will

20 have a higher fitness in any situation. A tragedy can also occur in plant competition

21 when the relevant structure is the root, and there is a reduction in fecundity through

22 investment in below-ground competition [7, 23].

23 Microbial biofilm production is an analogous situation, where production of

24 extracellular polymers help individual cells push their descendents upwards to gain 
1 much needed oxygen [24]. As a side effect, polymer production by these tall piles of

2 cells suffocate non-polymer producing neighbours [24]. This is analogous to plant

3 competition for light, in that vertical growth provides a competitive advantage over

4 conspecifics, but comes at an overall cost to the group: individuals which produce

5 polymers create a competitive environment which will lower overall group

6 productivity.

7 Bacteriocin production in bacteria may likewise be seen as a tragedy of the commons.

8 The production of bacteriocins kill other conspecifics, as well as the focal individual

$9 \quad[25,26]$, but can benefit immune clonemates at the expense of susceptible, unrelated

10 bacteria, which are the target of the bacteriocins. Bacteriocin production creates a

11 situation where group productivity is reduced: while the individuals which produce

12 the antibiotics stand to benefit, the group would do better if everyone restrained from

13 producing bacteriocins. In this case, the social good is living in a bacteriocin-free

14 environment, and this good is destroyed when all individuals produce bacteriocins. It

15 is worthwhile noting that bacteriocin production is also susceptible to a type 2 a social

16 goods tragedy, in that it may be advantageous for immune bacteria to cheat by

17 refraining from producing bacteriocins themselves [e.g. 27]. Indeed, the same

18 behaviour may often include conflict over multiple types of resources and hence

19 different types of tragedy.

Collapsing and component tragedies

21 The tragedy of the commons is commonly defined as a situation in which the selfish

22 actions of individuals result in the complete collapse of the resource over which they

23 are competing [1]. It is therefore important to add another layer of classification: how

24 the tragedy affects the productivity of a group (note that the term 'group' should be 
1 interpreted widely, extending to populations or species, depending on the scale and consequences of interactions between individuals).

3 As such, we define a "collapsing" tragedy as a situation where selfish individual

4 behaviour results in the entire resource vanishing (figure 1). For example, if the

5 currency is a social good formed by cooperation, collapse would mean that the group

6 loses the cooperative behaviour in question, and the social good ceases to exist. This

7 type of tragedy can lead to the extinction of the whole group, if the resource or the

8 social good was essential for its survival. An example of a "collapsing" tragedy is

9 worker reproduction in the Cape honey bee, where workers cease to help the colony

10 and instead invest in their own selfish reproduction, leading to very few individuals

11 becoming workers, and in turn, colony collapse [28].

12 Losing the resource completely is the most obvious form of a tragedy of the

13 commons, but empirically it is difficult to observe resources that have already

14 collapsed. A slightly weaker form of the tragedy of the commons occurs when the

15 resource has been depleted, but not to the extent that it disappears completely. We

16 define such a tragedy as the "component" tragedy, the word "component" being

17 borrowed from the Allee effect literature [29]. A component Allee effect is a density-

18 dependent process which reduces some component of fitness at low densities, and it

19 differs from demographic Allee effects in that the component Allee effect does not

20 necessarily diminish population growth, because other fitness components might

21 compensate. Component tragedies similarly result in a lower average fitness for the

22 group, as a result of selfish competition, but the group is still able to persist on the

23 resource in question (type 1 in Table 2) or benefit to some degree from the social

$24 \operatorname{good}($ type 2 and $2 \mathrm{~b}$ in table 2): the resource has not disappeared completely. Figure 1 
1 shows the conceptual difference between a component and a collapsing tragedy of the commons.

3 Component tragedies are likely to be very common (Table 1), as they simply reflect

4 the argument from the levels of selection debate that individual-level selection is

5 usually stronger than higher-level selection. One could argue that a too broad

6 definition renders a term less useful — indeed, whenever there is conflict between

7 individual and common good, the latter is expected to be sacrificed to some extent at

8 least. However, not all competitive scenarios lead to component tragedies (see Box 2).

9 Therefore, there is no tautology. Instead, identifying whether and under which

10 conditions such tragedies occur should be useful. Likewise, it is important to

11 differentiate between component and collapsing tragedies.

12 Interestingly, the same trait may be observed at many points of the continuum

13 between component tragedy and collapse. An example of this is caste fate in social

14 insects [9]: if all individuals become queens, the colony breaks down and a collapsing

15 tragedy is reached [28]. However, a partial resolution of the conflict turns the

16 situation into a component tragedy, as in Melipona bees, where more workers than the

17 colony optimum, but not all, become queens. This demonstrates that a component

18 tragedy is a relative concept: a decrease in group fitness compared to a hypothetical

19 situation in which individuals would behave "unselfishly". Indeed, what counts as

20 zero selfishness is a question with many possible answers. A sensible suggestion [8] is

21 that extent of a given tragedy could be measured as the deviation in group success

22 from that of a group in which individuals share the same interests and behave in a way

23 that is optimal for the group. In some cases, it can also be useful to quantify the 
1 opposite deviation, i.e. how far away is the group resource from complete collapse $2[30]$.

\section{Resolving the tragedy}

4 One of the main advantages of using the tragedy of the commons as an analogy in

5 evolutionary biology is that it forces us to ask the question why a tragedy of the

6 commons is not observed in a particular scenario [Table 1, 14, 30]. The fact that we

7 can observe significant amounts of cooperation despite the selfish interests of free

8 riders and cheaters raises the question of why component tragedies do not always

9 become collapsing tragedies, or why individuals in some cases cooperate so diligently

10 that even component tragedies are absent. The latter can be defined as a 'resolved

11 conflict' and is illustrated by cases of no significant colony-level costs of conflicts in

12 insect colonies [30]

13 Restraining may be individually optimal

14 By definition, a tragedy of the commons will not arise if there are direct benefits to 15 restraint. Therefore, apparently 'resolved' tragedies may, upon examination, turn out

16 not to be tragedies in the first place. Direct benefits of restraint behaviour are

17 especially likely to occur with social goods. For example, in sentinel behaviour in

18 meerkats, cheating may not confer benefits if vigilant individuals have a direct

19 personal advantage from being watchful [21].

\section{Population structure and kin selection}

21 One of the most commonly invoked mechanisms whereby conflicts may be resolved 22 — both fully or partially (i.e. leading to component rather than collapsing tragedy) - 
1 is kin selection [31]. In the absence of policing mechanisms, if individuals interact

2 locally with other highly related individuals, but compete for resources with all

3 individuals in a population, competitive restraint will be favoured [32]. Kin selection

4 (also mathematically interpretable as group selection [e.g. 15]) is likely to be

5 important in any situation where populations are structured in some way [33], such as

6 into groups [34] or in space [35]. Population structure helps to align the interests of

7 the individual with the interests of the group. This means that any reduction in group

8 productivity which results from individual-level selfishness will come at an inclusive

9 fitness cost to the focal individual, and hence over-exploiting a common resource will

10 be less beneficial. As a result, groups of related individuals which show restraint in

11 competition over a common resource will be favoured over groups in which

12 individual-level competition results in a tragedy of the commons.

\section{Coercion and punishment}

14 Coercion and punishment are among the most widely studied mechanisms for

15 avoiding a tragedy of the commons, both in the evolutionary literature $[6,36-38]$ as

16 well as in human sociobiology studies [e.g. 38]. These factors play a part in private

17 ownership of the resource (e.g. attempts to steal are punished) as well as

18 governmental control of resources [1] through the manipulation of payoffs (e. g. via

19 taxes). Coercion (where individuals manipulate and put pressure on others) has been

20 shown to be a potential force in altering the payoffs in animal societies [6]. Perhaps

21 the most sophisticated examples can be found in social insect colonies, where

22 "policing" individuals ensure that colony workers act to the benefit of the whole

23 colony and do not reproduce for their own selfish interest: worker-laid eggs are

24 regularly eaten by other workers [39]. 
1 While punishment can undoubtedly stabilize cooperation, for example between

2 legumes and their rhizome bacteria [40], it is interesting to note that such behaviour

3 also can be subject to a social goods tragedy of the commons in itself. We face a

4 second-order free-rider problem: when punishment is costly to the punisher, there is

5 an individual-level temptation not to punish cheaters [e.g. 41]. As such, higher-order

6 punishment (punishing individuals who do not punish) may be needed in such a

7 scenario [41]. But because this raises the same free-rider question at a higher level

8 (i.e. why not save energy by not punishing those who do not punish), punishment is

9 undoubtedly easier to explain in cases in which the punishing act itself is not costly,

10 such as egg-eating by policing workers, or when punishers receive more cooperation

11 from others [42].

Diminishing returns and ecological feedbacks

13 The benefits from overexploiting a resource are not always linear: they often diminish

14 as individuals try to compete more intensely for them. Diminishing returns can

15 therefore prevent a tragedy by reducing the overall benefit gained from increasingly

16 investing in a selfish behaviours [e.g. 8]. Diminishing returns are likely to be common

17 in a range of organisms, particularly when the individuals cannot make full use of the

18 extra resources that they acquire [8]. For example, the reproductive benefit of

19 possessing an ever-increasing territory is very likely diminishing: extremely large

20 territories prevent the individual from utilizing all its resources because other factors

21 become limiting (ultimately, speed of travel while foraging could prevent collecting

22 all resources). Thus, diminishing returns may put a break on overexploitation.

23 Diminishing returns may also resolve potential public good tragedies, as in the case of

24 blood sharing by vampire bats. Hungry bats need blood much more than ones that 
1 have recently fed, and this diminishing benefit of the state of an individual can alter

2 the balance of reciprocal aid by diminishing the benefit gained by a cheater who will

3 not share with other individuals even when it has fed properly [8].

4 Feedback between the size of the population (or group) and the intensity of conflict

$5[43,44]$ is a related phenomenon that is also likely to be important in reducing the

6 intensity of conflicts. If conflict and competition have a negative impact on the

7 number of individuals in a population, then this will automatically change the number

8 of individuals there are to interact with, ultimately affecting the structure of the

9 "game" [43]. Thus, selective pressures differ between low densities and high

10 densities, creating a feedback between adaptive individual behaviour and population

11 density. The strength of this feedback could therefore have an influence on the

12 strength of the conflict itself, thereby preventing a collapsing tragedy [43]. A potential

13 example is quorum sensing in bacteriocin production [45], where individual bacteria

14 reduce their production of bacteriocins when the population density is low.

\section{What if the tragedy is not resolved?}

16 Collapsing tragedies can be difficult to observe because they often destroy the study

17 object (the group or population, or the behavioural function that creates public goods).

18 However, this does not necessarily transfer the subject to evolutionary oblivion when

19 we consider that extinctions may have consequences for higher levels of selection,

20 such as group selection or species-level selection $[14,34,46]$. Recent work

21 demonstrates the potential for so-called evolutionary suicide [see 11]: precisely

22 because individual-level selection typically prevails over higher-level selection,

23 evolution is predicted to favour selfish individuals to the extent that it can lead to

24 extinction of higher-level biological structures. Cancer, a selfish form of cell growth 
1 [47], can kill individual organisms. Similarly if individual-level conflict can cause

2 population extinction, collapsing tragedies may have a large effect on species

3 persistence: those overexploiting common goods are denied prolonged existence. This

4 may result in selection at the species level [11, 46, 48].

5 Species-level selection can thus act as a "conflict limiting" mechanism if species that

6 have evolved high levels of conflict are driven extinct sooner than species in which

7 conflicts are milder [49]. Recent results suggest that even if actual evolutionary

8 suicide is not occurring, species with strong conflicts can render themselves

9 vulnerable to competitive exclusion, and thus competition with other species can

10 dramatically affect species persistence [e.g. 48, 50].

11 If the tragedy of the commons can act as a selective force at the level of the species,

12 we would expect to observe traits which limit or resolve the tragedy. Extant

13 organisms are expected to have robust mechanisms against at least the most

14 commonly occurring cheater mutants, as any collapsing tragedies that have occurred

15 have weeded out populations that lack such mechanisms. For example, in social

16 amoebas, certain cheating genotypes cannot proliferate because of pleiotropic effects

17 preventing spore formation [51]. It is possible that such genetic architecture, which

18 constrains cheating, could be selected for at the species level [48].

\section{Conclusion}

20 Hardin's analogy remains a powerful one for describing how the selfish interests of

21 individuals can bring about costs to all members of a group or population. Whether or

22 not such conflicts are fully resolved, remain at the state of a component tragedy, or

23 lead to a total collapse in group productivity, is a major question that has implications 
1 for social evolution, levels of selection, ecology of resource use, and several other

2 important phenomena. The rising tide of research, in the context of the tragedy of the

3 commons, will prove most useful if the types of tragedies involved are clearly

4 defined, and if the studies provide a clear scale for calculating how far the group-level

5 costs are from their possible minima or maxima.

6 Perhaps the most challenging question lies in addressing the relative frequency at

7 which tragedies arise with or without mechanisms to prevent them from reaching total

8 collapses. Groups subject to a total collapse have a far shorter lifespan, which makes

9 them difficult to study. In the light of ever-growing environmental concerns, thinking

10 about the tragedy of the commons in evolutionary biology is of interest not only

11 because of these evolutionary implications, but also because of the applied analogy to

12 human societies dealing with environmental and other public goods problems (box 1).

\section{Acknowledgements}

14 We thank Kevin Foster, Michael Hochberg, Laurent Keller and Michael Taborsky for

15 discussions. Kevin Foster, Andy Gardner, Heikki Helanterä, Michael Jennions, Stuart

16 West and two anonymous referees all gave very helpful comments on the manuscript.

17 Funding was from the Swiss National Science Foundation (DJR: grant 3100A0-

18105626 to M. Taborsky), The Academy of Finland (HK, KB), the Finnish School in

19 Conservation and Wildlife Biology (KB) and the Otto A. Malm foundation (KB).

\section{References}

21 1. Hardin, G. (1968) The tragedy of the commons. Science 162, 1243-1248

22 2. Lloyd, W.F. (1833) Two Lectures on the Checks to Population. Reprinted by

23 Augustus M. Kelly 
$13 . \quad$ Lack, D. (1954) The Natural Regulation of Animal Numbers. Oxford

2 University Press

3 4. Williams, G.C. (1966) Adaptation and Natural Selection: a critique of some

4 current evolutionary thought. Princeton University Press

5 5. Dawkins, R. (1976) The Selfish Gene. Oxford University Press

66 Frank, S.A. (1995) Mutual policing and repression of competition in the

7 evolution of cooperative groups. Nature $377,520-522$

87 . Gersani, M., et al. (2001) Tragedy of the commons as a result of root

9 competition. Journal of Ecology 89, 660-669

10 8. Foster, K.R. (2004) Diminishing returns in social evolution: the not-so-tragic

11 commons. Journal of Evolutionary Biology 17, 1058-1072

$129 . \quad$ Wenseleers, T., and Ratnieks, F.L.W. (2004) Tragedy of the commons in

13 Melipona bees. Proceedings of the Royal Society of London B 271, S310-S312

14 10. Falster, D.S., and Westoby, M. (2003) Plant height and evolutionary games.

15 Trends in Ecology and Evolution 18, 337-343

16 11. Rankin, D.J., and López-Sepulcre, A. (2005) Can adaptation lead to

17 extinction? Oikos $111,616-619$

18 12. Kerr, B., et al. (2006) Local migration promoted competitive restraint in a

19 host-pathogen "tragedy of the commons". Nature 442, 75-78

20 13. Rankin, D.J., and Kokko, H. (2006) Sex, death and tragedy. Trends in Ecology

21 and Evolution 21, 225-226

22 14. Leigh, E.G. (1977) How does selection reconcile individual advantage with

23 the good of the group? Proceedings of the National Academy of Sciences 74, 4542-

244546. 
1 15. West, S.A., et al. (2007) Social semantics: altruism, cooperation, mutualism,

2 strong reciprocity and group selection. Journal of Evolutionary Biology 20, 415-432

3 16. Hardin, R. (1971) Collective Action As an Agreeable n-Prisoners' Dilemma.

4 Behavioral Science 16, 472-481

5 17. Frank, S.A. (1996) Models of parasite virulence. Quarterly Review of Biology

$6 \quad 71,37-78$

7 18. Dionisio, F., and Gordo, I. (2006) The tragedy of the commons, the public

8 goods dilemma, and the meaning of rivalry and exludability in evolutionary biology.

9 Evolutionary Ecology Research 8, 321-332

10 19. Fiegna, F., and Velicer, G.J. (2003) Competitive fates of bacterial social

11 parasites: persistence and self-induced extinction of Myxococcus xanthus cheaters.

12 Proceedings of the Royal Society of London B 270, 1527-1534

13 20. Frank, S.A. (1998) Foundations of Social Evolution. Princeton University

14 Press

15 21. Clutton-Brock, T.H., et al. (1999) Selfish sentinels in cooperative mammals.

16 Science 284, 1640-1644

17 22. Greig, D., and Travisano, M. (2004) The Prisoner's Dilemma and

18 polymorphism in yeast SUC genes. Proceedings of the Royal Society of London B

$19 \quad 271, \mathrm{~S} 25-\mathrm{S} 26$

20 23. Dudley, S.A., and File, A.L. (2007) Kin recognition in an annual plant.

21 Biology Letters 3, 435-438

22 24. Xavier, J.B., and Foster, K.R. (2007) Cooperation and conflict in microbial

23 biofilms. Proceedings of the National Acedmy of Sciences of the USA 104, 876-881

24 25. Gardner, A., et al. (2004) Bacteriocins, spite and virulence. Proceedings of the

25 Royal Society of London B 271, 1529-1535 
$126 . \quad$ Riley, M.A., and Wertz, J.E. (2002) Bacteriocins: evolution, ecology and

2 application. Annual Review of Microbiology 56, 117-137

3 27. West, S.A., et al. (2006) Social evolution theory for microorganisms. Nature

$4 \quad$ Reviews Microbiology 4, 597-607

5 28. Martin, S.J., et al. (2002) Parasitic Cape honeybee workers, Apis mellifera

6 capensis, evade policing. Nature 415, 163-165

7 29. Berec, L., et al. (2007) Multiple Allee effects and population management.

$8 \quad$ Trends in Ecology and Evolution 22, 185-191

9 30. Ratnieks, F.L.W., et al. (2006) Conflict resolution in insect societies. Annual

10 Review of Entomology 51, 581-608

11 31. Hamilton, W.D. (1964) The genetical evolution of social behavior, I and II.

12 Journal of Theoretical Biology 7, 1-52

13 32. Taylor, P.D., et al. (2007) Evolution of cooperation in a finite homogeneous

14 graph. Nature 447, 469-472

15 33. Foster, K.R., et al. (2006) Kin selection is the key to altruism. Trends in

16 Ecology and Evolution 21, 57-60

17 34. Wilson, D.S. (1975) A theory of group selection. Proceedings of the National 18 Academy of Sciences 72, 143-146

19 35. Nowak, M.A., and May, R.M. (1992) Evolutionary games and spatial chaos.

$20 \quad$ Nature 359,826

21 36. Clutton-Brock, T., and Parker, G. (1995) Punishment in Animal Societies.

22 Nature 373, 209-216

23 37. Ratnieks, F.L.W., and Wenseleers, T. (2005) Policing insect societies. Science $24 \quad 307,54-56$ 
1 38. Fehr, E., and Gachter, S. (2002) Altruistic punishment in humans. Nature 415, $2 \quad 137-140$

3 39. Wenseleers, T., et al. (2004) Worker reproduction and policing in insect

4 societies: an ESS analysis. Journal of Evolutionary Biology 17, 1035-1047

5 40. Kiers, E.T., et al. (2006) Measured sanctions: legume hosts detect quantitative

6 variation in rhizobium cooperation and punish accordingly. Evolutionary Ecology

$7 \quad$ Research 8, 1077-1086

8 41. Hauert, C., et al. (2007) Via Freedom to Coercion: The Emergence of Costly

$9 \quad$ Punishment. Science 316, 1905-1907

10 42. Gardner, A., and West, S.A. (2004) Cooperation and punishment, especially in 11 humans. American Naturalist 164, 753-764

12 43. Rankin, D.J. (2007) Resolving the tragedy of the commons: the feedback

13 between population density and intraspecific conflict. Journal of Evolutionary

14 Biology 20, 173-180

15 44. Kokko, H., and López-Sepulcre, A. (2007) The ecogenetic link between

16 demography and evolution: can we bridge the gap between theory and data? Ecology

17 Letters

18 45. van der Ploeg, J.R. (2005) Regulation of Bacteriocin Production in

19 Streptococcus mutans by the quorum-sensing system required for development of

20 genetic competence. Journal of Bacteriology 187, 3980-3989

21 46. Okasha, S. (2006) Evolution and the Levels of Selection. Oxford University

22 Press

23 47. Frank, S.A., and Nowak, M.A. (2004) Problems of somatic mutation and

24 cancer. BioEssays 26, 291-299 
1 48. Rankin, D.J., et al. (2007) Species-level selecton reduces intraspecific

2 selfishness through competitive exclusion. Journal of Evolutionary Biology, In Press

3 49. Michod, R.E. (1999) Individuality, immortality and sex. In Levels of selection

4 in evolution (Keller, L., ed), Princeton University Press

5 50. Ciros-Pérez, J., et al. (2002) Resource competition and patterns of sexual

6 reproduction in sympatric sibling rotifer species. Oecologia 131, 35-42

7 51. Foster, K.R., et al. (2004) Pleiotropy as a mechanism to stabilise cooperation.

$8 \quad$ Nature 431, 693-696

9 52. Hutchings, J.A., and Reynolds, J.D. (2004) Marine fish population collapses:

10 consequences for recovery and extinction. BioScience 54, 297-309

11 53. Courchamp, G.F., et al. (2007) Rarity value and species extinction: the 12 anthropogenic Allee effect. PLoS Biology 4, 2405-2410

13 54. Myers, R.A., et al. (2007) Saving endangered whales at no cost. Current

14 Biology 17, R10-R11

15 55. Gell, F.R., and Roberts, C.M. (2003) Benefits beyond boundaries: the fishery 16 effects of marine reserves. Trends in Ecology and Evolution 18, 448-455

17 56. Penn, D.J. (2003) The evolutionary roots of our environmental problems:

18 toward a Darwinian ecology. The Quarterly Review of Biology 78, 275-301

19 57. Milinski, M., et al. (2006) Stabilizing the Earth's climate is not a losing game:

20 Supporting evidence from public goods experiments. Proceedings of the National

21 Academy of Sciences 103, 3994-3998

22 58. de Roode, J.C., et al. (2005) Virulence and competitive ability in genetically

23 diverse malaria infections. Proceedings of the National Academy of Sciences USA

$24 \quad 102,7624-7628$ 
1 59. Christen, M., and Milinski, M. (2005) The optimal foraging strategy of its

2 stickleback host constrains a parasite's complex life cycle. Behaviour 142, 979-996

3 60. Hodgson, D.J., et al. (2004) Host ecology determines the relative fitness of

4 virus genotypes in mixed-genotype nucleopolyhedrovirus infections. Journal of

$5 \quad$ Evolutionary Biology 17, 1018-1025

6 61. Brown, S.P., et al. (2002) Does multiple infection select for raised virulence?

$7 \quad$ Trends in Microbiology 10, 401-405

8 62. Denison, R.F., and Kiers, E.T. (2004) Lifestyle alternatives for rhizobia:

9 mutualism, parasitism, and forgoing symbiosis. . FEMS Microbiology Letters 237,

$10 \quad 187-193$

11 63. Rainey, P.B., and Rainey, K. (2003) Evolution of cooperation and conflict in 12 experimental bacterial populations. Nature $425,72-74$

13 64. Barclay, P. (2004) Trustworthiness and competitive altruism can also solve the

14 "tragedy of the commons". Evolution and Human Behaviour 25, 209-220

15 65. Milinski, M., et al. (2002) Reputation helps solve the 'tragedy of the

16 commons'. Nature 415

17 66. Semmann, D., et al. (2003) Volunteering leads to rock-paper-scissors

18 dynamics in a public goods game. Nature 425, 390-393

19 67. Foster, K.R., et al. (2002) The costs and benefits of being a chimera.

20 Proceedings of the Royal Society of London Series B-Biological Sciences 269, 2357-

$21 \quad 2362$

22 68. Zhang, D.Y., and Jiang, X.H. (2000) Costly solicitation, timing of offspring

23 conflict, and resource allocation in plants. Annals of Botany 86, 123-131.

24 69. Kura, T., and Yoda, K. (2001) Can voluntary nutritional gifts in seminal flow 25 evolve? Journal of Ethology 19, 9-15 
1 70. Dall, S.R.X., and Wedell, N. (2005) Evolutionary conflict: Sperm wars,

2 phantom inserninations. Current Biology 15, R801-R803

3 71. Fournier, D., et al. (2003) Colony sex ratios vary with breeding system but not

4 relatedness asymmetry in the facultatively polygynous ant, Pheidole pallidula.

$5 \quad$ Evolution 57, 1336-1342

6 72. Day, K.J., et al. (2003) The effects of spatial pattern of nutrient supply on the

7 early stages of growth in plant populations. Journal of Ecology 91, 305-315

8 73. Zea-Cabrera, E., et al. (2006) Tragedy of the commons in plant water use.

$9 \quad$ Water Resources Research 42, art. nr. W06D02

10 74. MacLean, R.C., and Gudelj, I. (2006) Resource competition and social conflict

11 in experimental populations of yeast. Nature 441, 498-501

12 75. Le Galliard, J.F., et al. (2005) Sex ratio bias, male aggression, and population

13 collapse in lizards. Proceedings of the National Academy of Sciences 102, 18231-

$14 \quad 18236$

15 76. Weining, C., et al. (2007) Antagonistic multilevel selection on size and

16 architecture in variable density settings. Evolution 61, 58-67

17

18 


\section{Glossary}

2 Cheater: An individual that gains a benefit from the collective, without investing in

3 the collective itself. These individuals can also be called "free-riders".

4 Collapsing tragedy: A situation in which selfish competition or free-riding escalates

5 until the resource is fully depleted. This can cause the collapse of the entire

6 population (i.e. extinction) if the resource was essential.

7 Component tragedy: A tragedy of the commons where escalated competition stops

8 before a collapse is reached.

9 Cooperation: The act of individuals paying an individual cost to contribute to a

10 collective benefit.

11 Individual-level selection: Selection acting at the level of the individual, to favour

12 individuals or genes which maximise their own fitness.

13 Over-exploitation: The depletion of a resource beyond the point where sustainable

14 use is possible.

15 Payoff: The overall benefits and costs gained from a particular strategy or behaviour.

16 Public good: A common resource which benefits all individuals in a group.

17 Resolution: Absence of tragedy, i.e. a situation where an inherent conflict causes no 18 group-level costs.

19 Social good: A public good that is shared by all members of a population or group

20 and is specifically created by cooperating individuals. 
1 Species-level selection: Selection that arises by differential extinction of species.

2 Tragedy of the commons: A situation where individual competition reduces the 3 resource over which individuals compete, resulting in lower overall fitness for all 4 members of a group or population.

5 Zero-sum game: A situation in which one individual's gain is matched by other 6 individuals' loss. Cutting a cake and chess are both examples of zero-sum games. 
1 Box 1. The tragedy of the commons in human environmental problems

2 Hardin's original essay dealt with both pollution and human over-population [1], but

3 the main point of his article was that a common resource would always be over-

4 exploited when utilized by self-interested individuals. Pollution, climate change and

5 overexploitation of fisheries all involve public goods suffering from the free-rider

6 problem, and are thus examples of the tragedy of the commons. For example, the

7 collapse of North Atlantic Cod [52] shows how easily common resources can be over-

8 exploited. People tend to value their own short-term self-interests over the long-term

9 good of the planet, so it is difficult to solve environmental problems by appealing to

10 individual goodwill only. Public awareness of resource limitation can even hasten

11 overexploitation: endangered species are traded at higher prices when their perceived

12 rarity increases [53]. Convincing participants to behave in a group-beneficial way

13 requires that individuals trust that the desired outcome is reachable and that free-riders

14 will not benefit. Such trust is difficult to create whenever data and experience show

15 otherwise.

16 A flipside of the tragedy of the commons is that avoiding it can often be beneficial to

17 the players involved, and can be described as win-win situations if policies are

18 improved. For example, right whales often become entangled in lobster fishing gear.

19 While fishermen are unkeen to reduce their income, a comparison of Canadian and

20 American lobster fisheries shows that reducing the risk of entanglement can be

21 achieved with no economic cost [54]: reducing fishing effort leads to improved yield

22 of lobsters per recruit. Similarly, despite considerable resistance and cynicism, marine

23 reserves (areas where fishing is prohibited) can benefit all fisherman, even over the

24 short-term [55]. Policy negotiations are difficult in these situations because people 
1 distrust others, but also because long-term benefits are rarely given sufficient weight

2 [56]. Without extensive education, such benefits are met with skepticism. For

3 example, the population dynamic arguments that relate catch effort to expected yield

4 in fisheries are not intuitively obvious. Easily perceived short-term individual benefits

5 would help to solve these problems. For example, using people's desire to improve

6 their social reputation could prevent exploitation of the common good, as is seen in

7 experimental "climate games" in which participants improve their reputation by

8 investing publicly to sustain the global climate [57].

9 The examples in table 1 show a wide range of tragedies, dealing with different

10 resources, from external resources to social goods created by either cooperation or

11 competitive restraint. What is striking is that organisms with little cognitive ability are

12 frequently able to resolve the tragedy with little or no cognitive or communicative

13 abilities. With our advantage of communication and foresight, solutions to human

14 tragedies of the commons should be within reach, but they are best solved, as Hardin

15 advocated, using "mutual coercion, mutually agreed upon". 
1 Table 1. Scenarios where the tragedy of the commons has been applied to evolutionary biology

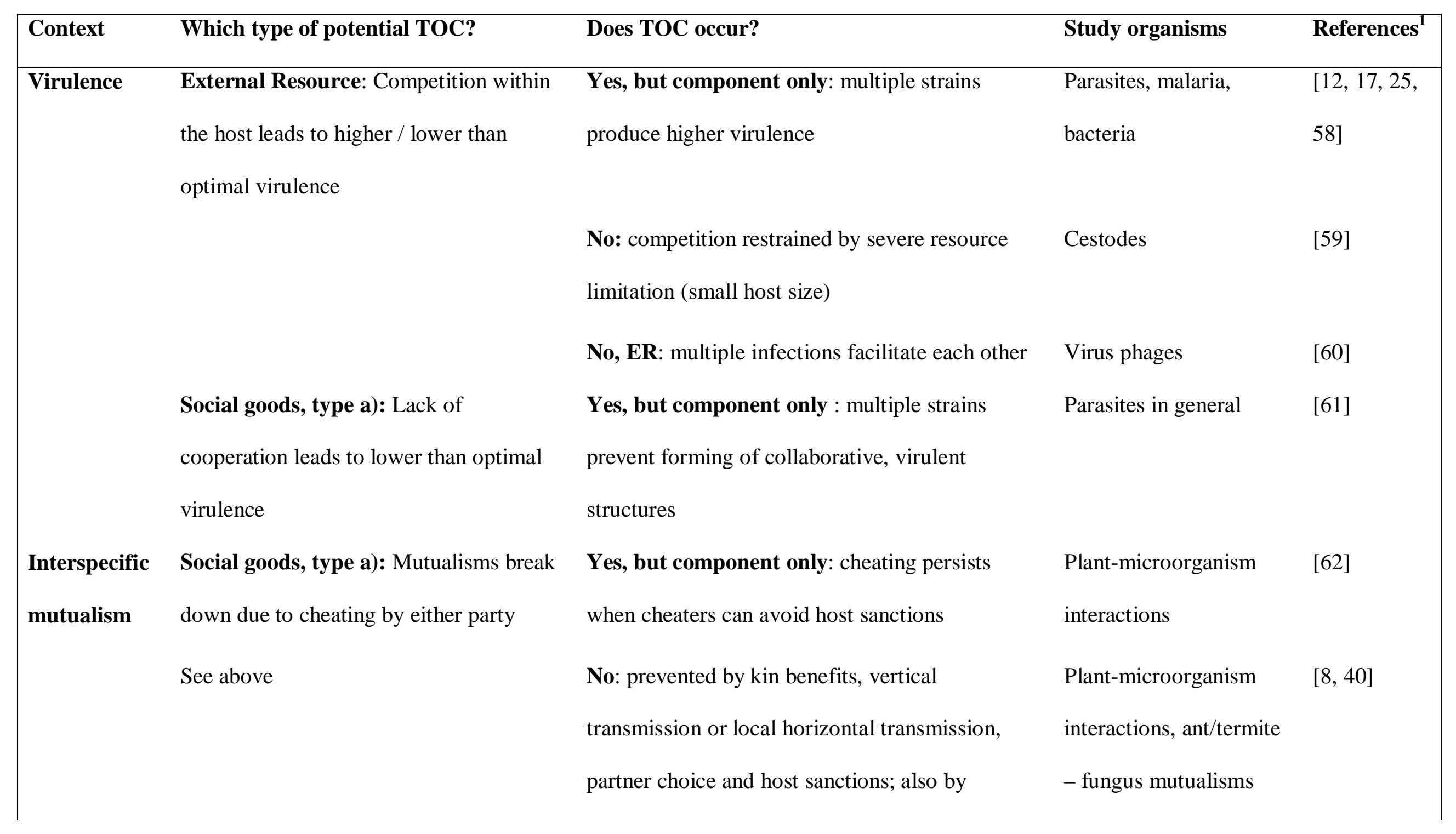


diminishing returns

Social Social Goods, type a): Cooperation

cooperation breaks down due to individual interests

and conflict

See above

See above

Social insects genomic

sex cromosomes over sex ratio

conflict
Social goods, type a): Selfish genetic
No: suppressed by "parliament of the genes",
Yes, but component only: when policing is

Social insects

impossible

No: prevented by policing or punishment

No: prevented by competition for reputation

No: prevented by rock-paper-scissor dynamics

Yes, but component only: chimeras are less

productive than single-clone individuals

Humans

Humans

Slime molds

Genomes

No: suppressed by autosomes 
elements promote unfair meiosis

Parent- $\quad$ Social goods, type b): Competition

offspring between offspring is costly

conflict

Sexual External Resource: Male harassment harms population

conflict

See above

Social goods, type b): Competition for mates leads to lower productivity

Social goods, type b): Large males are selected for although they have lower fecundity where genes not linked to the genes for meiotic

drive are selected to suppress the selfish

\section{behaviour}

Yes, but component only: offspring begging is

Plants

so costly that it reduces offspring size

Yes, but component only: male harassment Lizards

leads to population decline

No: prevented by reduced benefit of harassment Theory

at lower population sizes, or female counter-

adaptations

Yes, but component only: males invest in sperm Theory rather than nuptial gifts

Yes, collapse (theoretical prediction)

Fish 
Social Goods, type b): Both mating

partners in simultaneous hermaphrodites

prefer to play female

Competition Social Goods, type b): Reproductive

over sex-

ratio

competition forces queens to overproduce eggs, enabling workers to skew the sex

ratio against the optimum of queens

Resource Social Goods, type b): Competition for

competition light / resources forces plants to invest in

growth (roots / height) rather than

productivity (shoots / seeds)

See above

Social Goods, type b): Competition for water leads to high water uptake but low

yield

No: partners who refuse the male role are
No: prevented by human intervention (crop

selection)

Sea slugs

[70]

punished

Yes, but component only: sex ratio in multiple-

Ants

queen colonies is more female biased than the

queen optimum

Yes, but component only: production is

Plants

$[7,10,72]$

suboptimal

Yes, but component only: competition for water

Plants

favours aggressive water users although they

have lower productivity

No: prevented by kin selection and/or spatial 
segregation

Social Goods, type b): Competition

leads to high fixation rate of energy but

low yield

See above
Yes, but component only: species which face

Microbes

competition use high rate / low yield mechanisms

No: prevented by spatial structuring or costs to

Microbes

[74]

cheating

$2{ }^{1}$ The references included here explicitly describe their study systems as a tragedy of the commons. Clearly, many other studies address the same issues. 
1 Table 2. A 2 by 3 classification of the types resources prone to a tragedy of the commons

\begin{tabular}{|c|c|c|c|c|}
\hline \multicolumn{2}{|c|}{ Resource } & $\begin{array}{c}\text { Conceptual description } \\
\text { of resource }\end{array}$ & $\begin{array}{c}\text { Example of } \\
\text { resource }\end{array}$ & $\begin{array}{l}\text { Example of a } \\
\text { tragedy of the } \\
\text { commons } \\
\text { involving the } \\
\text { resource }\end{array}$ \\
\hline $\begin{array}{l}\text { Type } 1 \\
\text { A pre- } \\
\text { existing } \\
\text { resource }\end{array}$ & & $\begin{array}{l}\text { An extrinsic resource } \\
\text { over which individuals } \\
\text { in a group or } \\
\text { population compete }\end{array}$ & $\begin{array}{l}\text { Females (in } \\
\text { the context } \\
\text { of male- } \\
\text { male } \\
\text { competition) }\end{array}$ & $\begin{array}{l}\text { Male competition } \\
\text { for females leads } \\
\text { to decline in } \\
\text { female numbers } \\
{[13,75]}\end{array}$ \\
\hline & $\begin{array}{l}\text { Social Goods } \\
\text { - formed by } \\
\text { cooperation }\end{array}$ & $\begin{array}{l}\text { A cooperative } \\
\text { environment - social } \\
\text { goods, which are } \\
\text { formed by individuals } \\
\text { within a group } \\
\text { cooperating }\end{array}$ & $\begin{array}{l}\text { Cooperative } \\
\text { formation of } \\
\text { stalks }\end{array}$ & $\begin{array}{l}\text { Microbe cheaters, } \\
\text { which would } \\
\text { usually } \\
\text { cooperate, drive } \\
\text { the population } \\
\text { extinct [19] }\end{array}$ \\
\hline $\begin{array}{l}\text { Type } 2 \\
\text { Social } \\
\text { Goods }\end{array}$ & $\begin{array}{l}\text { Social goods } \\
\text { - formed by } \\
\text { restraining } \\
\text { from conflict }\end{array}$ & $\begin{array}{l}\text { A non-competitive } \\
\text { environment - } \\
\text { individuals restrain } \\
\text { from conflict }\end{array}$ & $\begin{array}{l}\text { Short plants, } \\
\text { which can } \\
\text { invest all } \\
\text { resources } \\
\text { towards } \\
\text { reproduction }\end{array}$ & $\begin{array}{l}\text { Competition for } \\
\text { light forces plants } \\
\text { to invest in } \\
\text { growth rather } \\
\text { than productivity } \\
{[10]}\end{array}$ \\
\hline
\end{tabular}


1 Figure 1. Component and collapsing tragedies. We define a collapsing tragedy (green

2 line) as one where complete selfishness causes the loss of all of the resource in

3 question. A component tragedy is one where selfishness reduces the resource, but not

4 to the extent where it is lost completely (blue line).

5

6

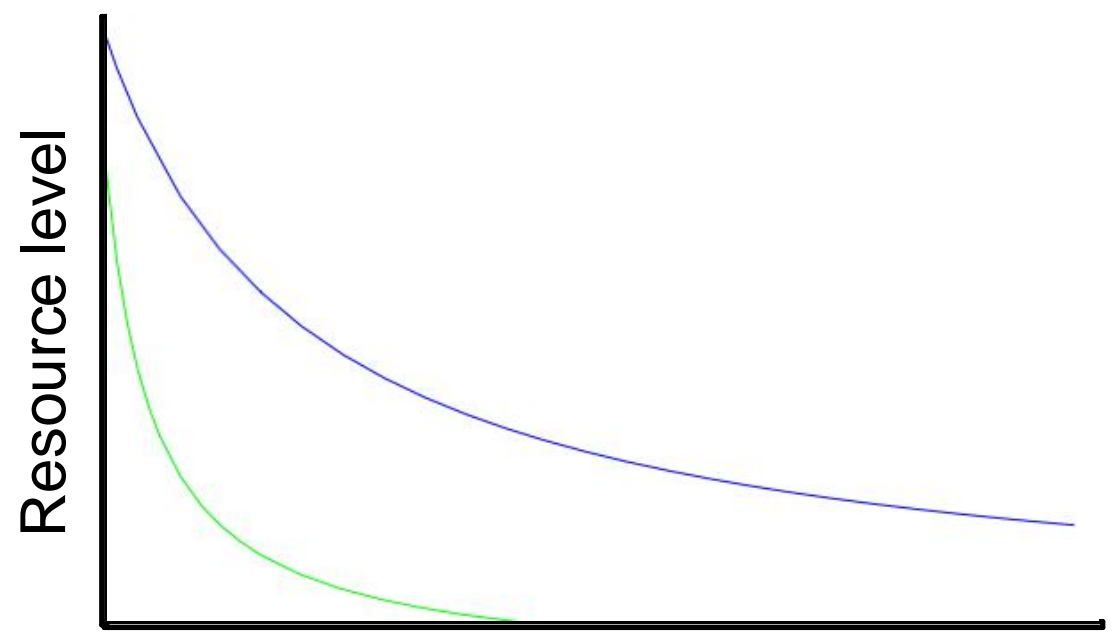

Individual Selfishness 
1 Figure 2. Examples of the three types of resources over which a tragedy of the

2 commons may occur. (a) Over-exploitation of a pre-existing resource (type 1 in table

3 2), shown here by virus phages overexploiting a host bacteria [12 ], (b) Dictyostelium

4 discoideum, where a tragedy of the commons may occur if too

5 many individuals invest in producing more spores, whilst abstaining from investing in

6 the stalk structure necessary for reproduction [67], (c) plant competition for light,

7 where a tragedy of the commons may occur when individuals forego the non-

8 competitive environment created by abstaining from growing taller [76]. Photos by B.

$9 \quad$ Kerr (a), K.R. Foster (b) \& D.J. Rankin (c).

(a)

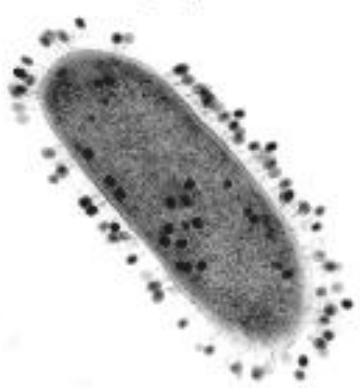

(b)

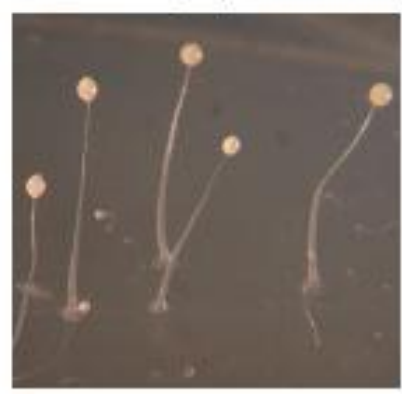

(c)

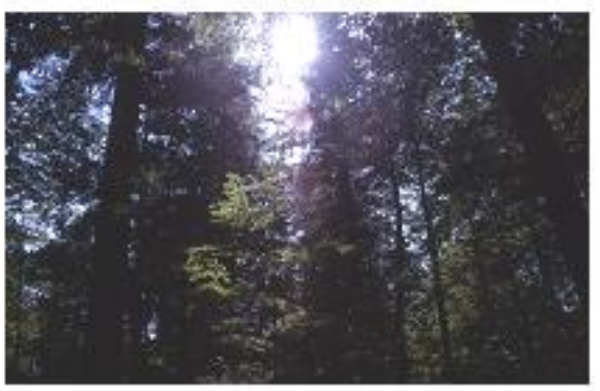

